\title{
Morfo-anatomia comparada de espécies da subtribo Coutoubeinae (Chironieae - Gentianaceae)
}

\author{
Marina Neves Delgado ${ }^{1,4}$,Aristéa Alves Azevedo², Gilmar Edilberto Valente ${ }^{2}$ e Maria Catarina Megumi Kasuya ${ }^{3}$
}

Recebido em 26/10/2008. Aceito em 21/01/2009

\begin{abstract}
RESUMO - (Morfo-anatomia comparada de espécies da subtribo Coutoubeinae (Chironieae - Gentianaceae)). O objetivo do trabalho é caracterizar a morfo-anatomia do corpo vegetativo de Deianira erubescens, Deianira pallescens, Deianira nervosa, Deianira chiquitana e Schultesia gracilis, visando fornecer subsídios à taxonomia e compreender algumas estratégias adaptativas. Coletaram-se amostras de indivíduos de Deianira no cerrado e de Schultesia no campo rupestre, MG. O material foi processado para observações em microscopia de luz. D. erubescens e $D$. pallescens apresentam folhas em rosetas e opostas cruzadas, concrescidas na base, ao longo do caule; $D$. chiquitana apresenta folhas concrescidas na base apenas na região proximal do caule e folhas opostas cruzadas livres; $D$. nervosa e $S$. gracilis apresentam folhas opostas cruzadas livres. No gênero Deianira são observadas raízes com crescimento secundário, sendo não usual em $D$. erubescens e D. nervosa e micorrizas arbusculares (MAs) do tipo Arum, exceto em $D$. nervosa; caule fistuloso em $D$. pallecens; folhas anfiestomáticas e mesofilo homogêneo, exceto em $D$. nervosa na qual são observadas folhas hipoestomáticas e mesofilo dorsiventral. $S$. gracilis apresenta raízes com aerênquima e MAs do tipo Paris; caule prismático, alado, fistuloso e folhas hipoestomáticas com mesofilo homogêneo. Caracteres anatômicos podem ser utilizados para distinção das espécies e podem contribuir para compreender estratégias adaptativas ao cerrado e campo rupestre. Palavras-chave: Anatomia, Deianira, Gentianaceae, Micorriza, Schultesia
\end{abstract}

\begin{abstract}
Compared morphoanatomy of species of the subtribe Coutoubeinae (Chironieae - Gentianaceae)). We characterized the morphology and anatomy of the vegetative body of Deianira erubescens, Deianira pallescens, Deianira nervosa, Deianira chiquitana and Schultesia gracilis to aid in the taxonomy and understanding of adaptive strategies. Samples of Deianira and Schultesia were collected from Cerrado and campo rupestre, MG. The material was processed for observation by light microscopy. D. erubescens and D. pallescens have rosulate, decussate leaves, concrescent at the base along the stem; $D$. chiquitana has concrescent leaves at the base in the proximal region of the stem and decussate leaves not fused; D. nervosa and $S$. gracilis have decussate leaves not fused. In the genus Deianira, there are roots with secondary growth, these are not usual in $D$. erubescens and $D$. nervosa and Arum-type arbuscular mycorrhizae (AM), except in D. nervosa; stems fistular in D. pallecens; amphistomatic leaves and homogenous mesophyll, except in D. nervosa where there are hypostomatic leaves and dorsiventral mesophyll. S. gracilis has roots with aerenchyma and Paris-type AM, stem prismatic, winged and fistular and hypostomatic leaves with homogenous mesophyll. Anatomical characters may be used successfully in the distinction of species and may be used to understand the adaptation to environment.
\end{abstract}

Key words: Anatomy, Deianira, Gentianaceae, Mycorrhyzae, Schultesia

\section{Introdução}

Gentianaceae é a terceira maior família da ordem Gentianales (Albert \& Struwe 2002) e possui distribuição cosmopolita, estando concentrada na região temperada (Sousa \& Lorenzi 2005), apesar das Américas do Sul e Central conterem a maior diversidade genérica (Struwe et al. 2002; Meszaros et al. 1996).

A tribo Chironieae compreende 159 espécies em 23 gêneros. As espécies da tribo são anuais, bianuais ou perenes com ciclo de vida curto. As folhas são simples, sésseis, raramente pecioladas e com formatos variados. As plantas podem apresentar filotaxia rosulada. Por meio de análises moleculares, os 23 gêneros da tribo Chironieae foram distribuídos em três subtribos: Chironiinae, Canscorinae e Coutoubeinae. A subtribo Coutoubeinae tem distribuição neotropical e compreende os gêneros Deianira, Schultesia, Coutoubea, Symphyllophyton e Xestaea (Struwe et al. 2002).

Deianira consiste em sete espécies, sendo que todas ocorrem no cerrado brasileiro e uma delas também ocorre na Bolívia. O porte herbáceo da planta e a presença de folhas em roseta e/ou folhas caulinares simples, decussadas, semi-amplexicaules ora de base livre ora concrescida são características importantes para a identificação do gênero (Guimarães 1977). Schultesia contém 15 espécies, principalmente distribuídas nas Américas Central e Sul, e uma espécie ocorrente na África ocidental (Struwe et al. 2002), sendo a América do Sul, principalmente o Brasil, o centro de diversidade do gênero. As espécies de Schultesia são ervas anuais com folhas longas e lanceoladas que crescem em locais abertos, brejos, campo rupestre, cerrado e veredas (Guimarães 2004). Coutoubea possui cinco espécies anuais ou perenes com breve ciclo de vida (Struwe et al. 2002) que estão distribuídas na região norte da América do Sul (Guimarães \& Klein 1985). Symphyllophyton apresenta apenas uma espécie que é endêmica da região sul do Brasil. Xestaea é também um gênero monotípico, cuja espécie se encontra nas regiões norte e central da América do Sul (Struwe et al. 2002).

O domínio do cerrado, formado por diferentes biomas como o cerrado e os campos rupestres (Coutinho 2002), apresenta em sua flora espécies de Deianira e Schultesia (Mendonça et al. 2007). Plantas do cerrado e dos campos rupestres estão submetidas à sazonalidade climática, alta irradiação solar, alta temperatura, baixa umidade relativa do ar e baixa disponibilidade de nutrientes minerais (Arens 1963; Giulietti et al. 1987; Furley \& Ratter 1988; Franco \& Lüttge 2002). Tais fatores abióticos típicos do cerrado e dos campos rupestres demandam grande investimento em estruturas subterrâneas e estratégias morfoanatômicas adaptativas às condições estressantes (Franco \& Lüttge 2002; Larcher

\footnotetext{
Universidade de Brasília, Departamento de Ecologia, Campus Universitário Darcy Ribeiro, Brasília, DF, Brasil

2 Universidade Federal de Viçosa, Departamento de Biologia Vegetal, Campus Universitário, Viçosa, MG, Brasil

3 Universidade Federal de Viçosa, Departamento de Microbiologia, Campus Universitário, Viçosa, MG, Brasil

4 Corresponding Author: mnevesdelgado@hotmail.com
} 
2004). Micorrizas são importantes adaptações radiculares, pois auxiliam as plantas na absorção de nutrientes e de água (Herrman et al. 2004), uma vez que proporcionam maior volume de solo explorado (Siqueira 2002). Durante a estação de estiagem, as camadas superficiais dos solos tornam-se secas (Franco 2002), uma vez que a baixa umidade relativa do ar e a alta temperatura no cerrado impõem uma alta demanda evaporativa (Franco 1998). Logo, a grande taxa de micorrização em herbáceas de cerrado (Detmann et al. 2008) pode ser justificada pelo incremento na absorção de água que é fundamental para as herbáceas.

Um dos maiores objetivos das pesquisas futuras das Gentianaceae deve ser a distinção entre as espécies da família (Albert \& Struwe 2002). Estudos moleculares foram desenvolvidos na tribo Chironieae visando à resolução da problemática taxonômica (Mansion \& Struwe 2004; Mansion 2004; Struwe et al. 2002). Apesar das filogenias moleculares da tribo Chironieae serem fortemente suportadas pelas seqüências matK e análises combinadas, não foram identificadas sinapomorfias morfológicas ou anatômicas do grupo (Albert \& Struwe 2002), o que justifica a difícil identificação imediata da tribo e das espécies que a compõem. Estudos anatômicos também podem contribuir para a taxonomia das espécies da família, tendo em vista a pequena variação morfológica e a restrita distribuição geográfica das espécies de Deianira que dificultam o estudo filogenético (Guimarães 1977) e taxonômico do grupo. Além disso, o gênero Schultesia apresenta problemas de nomenclatura, como Schultesia pallens que é sinonímia de Schultesia gracilis (Guimarães 2004) e a freqüente inclusão do gênero Xestaea em Schultesia apesar de ter sido retirado do grupo devido ao diferente padrão de exina no grão de pólen e análises de seqüência matK (Struwe et al. 2002). Por meio de análises morfológicas da subtribo Coutoubeinae, Deianira é grupo irmão de Symphyllophyton e Schultesia é grupo irmão de Coutoubea (Struwe et al. 2002). Logo, no presente trabalho escolheu-se uma espécie de Schultesia como grupo externo de Deianira para comparar anatomicamente as espécies. O estudo da anatomia de Deianira e Schultesia é também legitimado pela escassez de trabalhos sobre a anatomia do corpo vegetativo destes gêneros e pelo auxilio na compreensão das estratégias adaptativas (Dickison 2000) ao cerrado e campo rupestre, locais de ocorrência das espécies.

Diante do exposto, os objetivos gerais da pesquisa foram: selecionar caracteres que possam fornecer subsídio para a taxonomia da subtribo Coutoubeinae e avaliar os caracteres morfo-anatômicos que possam contribuir para a compreensão das estratégias adaptativas das espécies aos biomas cerrado e campo rupestre.

\section{Material e métodos}

Foram estudados os órgãos vegetativos de cinco espécies da subtribo Coutoubeinae (Chironieae): Deianira erubescens Cham. \& Schltdl., Deianira pallescens Cham. \& Schltdl., Deianira nervosa Cham. \& Schltdl., Deianira chiquitana Herzog e Schultesia gracilis Mart.
O material vegetal utilizado foi coletado em Minas Gerais, Brasil; no campo rupestre da Serra de Ouro Branco e no cerrado da Floresta Nacional de Paraopeba (FLONA). Exemplares férteis foram depositados no acervo do Herbário VIC da Universidade Federal de Viçosa (UFV): Deianira erubescens (VIC 31.368), Deianira pallescens (VIC 31.369), Deianira nervosa (VIC 19.405), Deianira chiquitana (VIC 19.406; VIC 31.367) e Schultesia gracilis (VIC 31.365).

Para estudos anatômicos foram coletados em cada área de estudo a parte aérea e o sistema radicular de pelo menos três indivíduos, de cada espécie. Em seguida, amostras da folha, do caule e da raiz foram fixadas em FAA $_{50}$ e FAA 70 e estocadas em etanol 70\% (Johansen 1940). A lâmina foliar foi amostrada nas regiões basal, mediana, apical e marginal. O caule foi amostrado nas regiões do segundo e terceiro entrenó e a raiz foi amostrada em regiões com crescimento secundário.

Para confecção de lâminas permanentes, amostras de folhas, caules e raízes foram incluídas em metacrilato (Historesin, Leica Instruments). Cortes transversais e longitudinais com 6-8 $\mu \mathrm{m}$ de espessura foram obtidos em micrótomo rotativo de avanço automático (modelo RM2155, Leica Microsystems Inc., Deerfield, USA) e corados com Azul de Toluidina (O’Brien \& McCully 1981).

Para estudos das características da epiderme, as folhas foram diafanizadas em solução de $\mathrm{NaOH} 10 \%$ e hipoclorito de sódio $20 \%$. As amostras foram coradas com Fuccina Básica, desidratadas em série etílica/xilólica e montadas em Permount (Berlyn \& Miksche 1976). Outra técnica para estudos da epiderme foi a dissociação, utilizando ácido nítrico e ácido crômico (1:1 v/v) (Johansen 1940).

A diafanização das raízes para estudos da associação micorrízica pode ser dificultada devido à intensa lignificação e pigmentação (Brundett et al. 1996). Portanto, a técnica de diafanização de raízes segundo Phillips \& Hayman (1970) foi empregada apenas em Schultesia gracilis, pois suas raízes eram as mais finas e as menos pigmentadas. Os fragmentos de raízes foram corados com Azul de Tripano e montados em Lactoglicerol.

Registros fotográficos foram efetuados usando câmara digital Sony H5 e fotomicroscópio Olympus AX70, equipado com sistema U-Photo do Laboratório de Anatomia Vegetal da UFV.

\section{Resultados}

Observações de campo - Representantes de Deianira erubescens (Fig. 1-2), Deianira chiquitana (Fig. 5-6) e Schultesia gracilis (Fig. 7) apresentam porte herbáceo enquanto que Deianira pallescens (Fig. 3-4) e Deianira nervosa (Fig. 8) apresentam porte herbáceo-arbustivo. $D$. erubescens, D. pallescens, D. chiquitana e D. nervosa possuem raízes profundas e pouco ramificadas. $D$. erubescens e $D$. pallescens também apresentam algumas vezes raízes tuberosas. Por outro lado, em $S$. gracilis as raízes são superficiais, finas e ramificadas. O caule é cilíndrico nas espécies estudadas de Deianira (Fig. 1, 4, 6, 8), sendo fistuloso em D. pallescens. Em S. gracilis, o caule é alado, fistuloso e quadrangular em secção transversal. Os representantes de D. erubescens (Fig. 1-2) e D. pallescens (Fig. 3-4) apresentam folhas carnosas dispostas em roseta e, ao longo do caule, são observadas folhas carnosas opostas cruzadas, concrescidas na base. Porém, as folhas opostas cruzadas são maiores em $D$. pallescens do que em $D$. erubescens. Em D. chiquitana (Fig. 5-6) na base do caule existem folhas concrescidas na base, lanceoladas e com nervuras salientes. Em D. chiquitana (Fig. 5-6) e em S. gracilis são observadas ao longo do caule folhas semi-amplexicaules, decussadas, membranáceas, de base livre e com disposição vertical em relação ao caule. Em Deianira nervosa as folhas são semi-amplexicaules, decussadas, coriáceas e com 
nervuras salientes, apresentando disposição perpendicular em relação ao caule.

Descrição anatômica - Todas as raízes coletadas das espécies de Deianira (Tab. 1) apresentam estrutura secundária, sendo observado crescimento secundário com atividade cambial do tipo não usual com floema interxilemático em Deianira erubescens e Deianira nervosa e do tipo usual em Deianira pallescens e Deianira chiquitana. A epiderme das raízes de D. erubescens (Fig. 9-10), D. pallescens (Fig. 11) e D. nervosa é descartada com algumas camadas de parênquima cortical. Nas três espécies citadas acima,
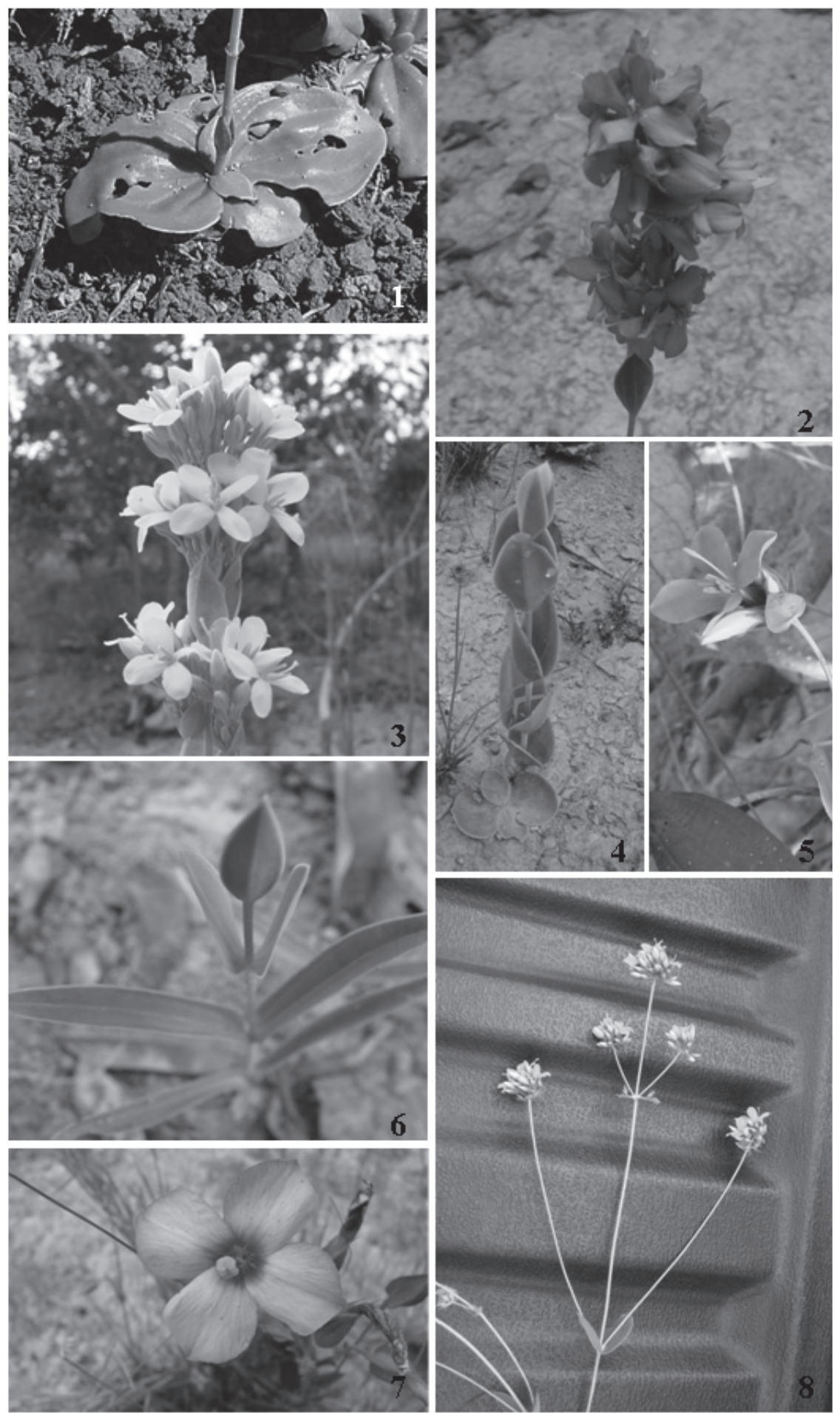

Figuras 1-8. Espécies estudadas da subtribo Coutoubeinae G. Don. 1-2. Deianira erubescens Cham. \& Schltdl. 3-4. Deianira pallescens Cham. \& Schltdl. 5-6. Deianira chiquitana Herzog. 7. Schultesia gracilis Mart. 8. Deianira nervosa Cham. \& Schltdl. 
a epiderme é substituída por células corticais de formato alongado no sentido anticlinal, já na raiz secundária de $D$. chiquitana a epiderme permanece (Fig. 12-13). Em nenhuma das espécies analisadas, pêlos radiculares são detectados no material amostrado. $\mathrm{O}$ córtex da raiz de $D$. pallescens (Fig. 11) e D. chiquitana (Fig. 12-13) é formado apenas por parênquima propriamente dito. $\mathrm{O}$ córtex de $D$. erubescens (Fig. 10) e de D. nervosa (Fig. 14) apresenta, além do parênquima fundamental, esclereídes. Em D. pallescens e em D. chiquitana, o córtex parenquimático apresenta conteúdo amilífero. Micorrizas arbusculares (MAs) do tipo Arum são visualizadas nas raízes das espécies de Deianira com crescimento secundário inicial (Fig. 12-13), exceto em $D$. nervosa. As MAs são descartadas junto com camadas de córtex em D. erubescens (Fig. 10) e D. pallescens (Fig. 11). Nas raízes analisadas não são visualizadas estrias de Caspary na endoderme. Em D. erubescens e D. nervosa (Fig. 14-15), o câmbio único e permanente produz esporadicamente faixas de floema inclusas no xilema secundário. $D$. pallescens e $D$. chiquitana que apresentam crescimento usual possuem apenas floema secundário externo ao xilema secundário e, nessas espécies, não se observa diferenciação de um felogênio. Não foi observada região de origem de raízes laterais.

As raízes de Schultesia gracilis (Tab. 1) são extremamente finas e apresentam estrutura secundária, com epiderme persistente (Fig. 24). O córtex é formado por aerênquima (Fig. 24) no qual são observadas micorrizas arbusculares do tipo Paris (Fig. 25) e vesículas (Fig. 26). Uma endoderme diferenciada não é visualizada nas raízes.
O caule das espécies analisadas de Deianira (Tab. 2) é cilíndrico. A epiderme é uniestratificada, com células de paredes periclinais externas espessas e cutícula fina e lisa. Em secção transversal, as células epidérmicas do caule são tabulares em Deianira erubescens e Deianira nervosa e altas em Deianira pallecens e Deianira chiquitana. O córtex caulinar é parenquimático. A região pericíclica apresenta esclereídes em $D$. erubescens, $D$. pallescens e $D$. nervosa. $\mathrm{O}$ sistema vascular apresenta floema externo e interno. A medula é conspícua e constituída por células parenquimáticas, sendo fistulosa em $D$. pallescens.

O caule de Schultesia gracilis (Tab. 2) é alado e quadrangular, em secção transversal (Fig. 27), com epiderme uniestratificada formada por células cujas paredes periclinais externas são sinuosas com cutícula fina e ornamentada. Em secção transversal, as células epidérmicas do caule são altas. Em $S$. gracilis, o córtex caulinar, constituído por parênquima, apresenta endoderme típica, na qual são visualizadas estrias de Caspary. O sistema vascular apresenta floema externo e interno com medula conspícua, parenquimática e fistulosa (Fig. 27-28).

Nas folhas das espécies de Deianira (Tab. 3), a parede periclinal externa das células da epiderme é lisa, sendo fina nas folhas das rosetas de Deianira erubescens e Deianira pallescens e espessa nas folhas opostas cruzadas de $D$. erubescens, D. pallescens, Deianira nervosa e Deianira chiquitana. A cutícula fina e lisa é observada em $D$. erubescens, $D$. pallescens e $D$. chiquitana enquanto em $D$. nervosa são observadas ornamentações cuticulares. Em corte transversal, as células epidérmicas das folhas da roseta são tabulares

Tabela 1. Características morfo-anatômicas da raiz de Deianira erubescens Cham. \& Schltdl., Deianira pallescens Cham. \& Schltdl., Deianira nervosa Cham. \& Schltdl., Deianira chiquitana Herzog e Schultesia gracilis Mart. $1=$ presença; $0=$ ausência; AM = micorriza arbuscular.

\begin{tabular}{|c|c|c|c|c|c|}
\hline Tribo Chironieae / Espécies & D. erubescens & D. pallescens & D. nervosa & D. chiquitana & S. gracilis \\
\hline Crescimento usual & 0 & 1 & 0 & 1 & 1 \\
\hline Crescimento não usual interfloemático & 1 & 0 & 1 & 0 & 0 \\
\hline Córtex com parênquima propriamente dito & 1 & 1 & 1 & 1 & 0 \\
\hline Córtex com aerênquima & 0 & 0 & 0 & 0 & 1 \\
\hline Córtex parenquimático com MA do tipo Paris & 0 & 0 & 0 & 0 & 1 \\
\hline Córtex parenquimático com MA do tipo Arum & 1 & 1 & 0 & 1 & 0 \\
\hline Córtex com esclereídes & 0 & 0 & 1 & 0 & 0 \\
\hline Córtex com fibras & 1 & 0 & 0 & 0 & 0 \\
\hline Córtex com amido & 0 & 1 & 0 & 1 & 0 \\
\hline
\end{tabular}

Tabela 2. Características morfo-anatômicas do caule de Deianira erubescens Cham. \& Schltdl., Deianira pallescens Cham. \& Schltdl., Deianira nervosa Cham. \& Schltdl., Deianira chiquitana Herzog e Schultesia gracilis Mart. 1 = presença; 0 = ausência.

\begin{tabular}{|c|c|c|c|c|c|}
\hline Tribo Chironieae / Espécies & D. erubescens & D. pallescens & D. nervosa & D. chiquitana & S. gracilis \\
\hline Caule quadrangular e alado & 0 & 0 & 0 & 0 & 1 \\
\hline Caule cilíndrico & 1 & 1 & 1 & 1 & 0 \\
\hline Células epidérmicas tabulares & 1 & 0 & 1 & 0 & 0 \\
\hline Células epidérmicas altas & 0 & 1 & 0 & 1 & 1 \\
\hline Parede periclinal externa espessa & 1 & 1 & 1 & 1 & 0 \\
\hline Cutícula lisa & 1 & 1 & 1 & 1 & 0 \\
\hline Cutícula ornamentada & 0 & 0 & 0 & 0 & 1 \\
\hline Região pericíclica formada por esclereídes & 1 & 1 & 1 & 0 & 0 \\
\hline Endoderme com estrias de Caspary & 1 & 0 & 0 & 0 & 1 \\
\hline Xilema muito desenvolvido & 1 & 0 & 1 & 0 & 1 \\
\hline Xilema pouco desenvolvido & 0 & 1 & 0 & 1 & 0 \\
\hline Medula fistulosa & 0 & 1 & 0 & 0 & 1 \\
\hline
\end{tabular}


em $D$. erubescens e isodiamétricas em $D$. pallescens. Nas regiões basal, mediana e apical de uma mesma folha oposta cruzada são visualizadas variações no formato das células epidérmicas em corte transversal, como ocorre em D. erubescens. Nesta espécie, as células epidérmicas são isodiamétricas nas regiões basal e medianas, e tabulares no ápice das folhas opostas cruzadas. As folhas são anfiestomáticas em $D$. pallescens, $D$. erubecens e $D$. chiquitana enquanto em $D$. nervosa elas são hipoestomáticas. Os estômatos estão no mesmo nível das demais células epidérmicas em todas as espécies e o tipo preponderante de estômatos encontrados nas folhas opostas cruzadas é o anisocítico.

Em seção transversal do limbo, nota-se que o mesofilo é homogêneo e armazenador de água, com células parenquimáticas isodiamétricas e bastantes volumosas em Deianira pallescens (Fig. 16) e Deianira erubescens (Fig.
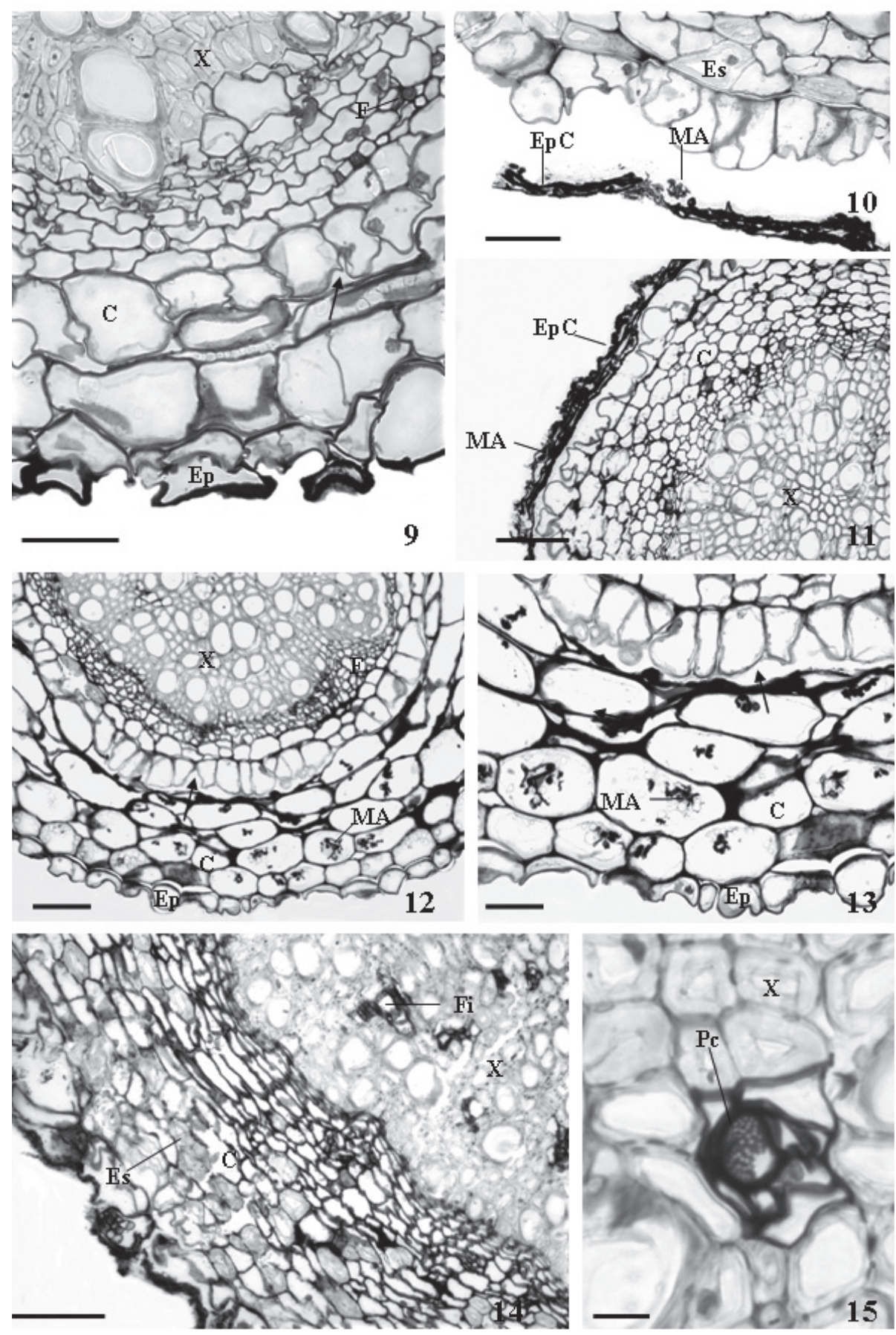

Figuras 9-15. Raiz. 9-10: Deianira erubescens Cham. \& Schltdl. 11: Deianira pallescens Cham. \& Schltdl. 12-13. Deianira chiquitana Herzog. 14-15. Deianira nervosa Cham. \& Schltdl. Ep- epiderme, C- córtex, F- floema, X-xilema, Seta- local de descarte do córtex, EpC- epiderme e córtex descartados, MA- micorriza arbuscular, Es- esclereide, Fi- floema incluso, Pc- placa crivada. Escalas $=50 \mu \mathrm{m}(9,10,13) ; 100 \mu \mathrm{m}(11,12,14) ; 10 \mu \mathrm{m}(15)$. 
18). Em Deianira chiquitana, observa-se mesofilo homogêneo formado apenas por parênquima clorofiliano (Fig. 20) enquanto que o mesofilo dorsiventral é observado em Deianira nervosa. A nervura mediana apresenta conformação distinta entre as espécies, sendo mais proeminente em D. chiquitana (Fig. 20) do que em D. pallescens (Fig. 16), D. erubescens (Fig. 18) e D. nervosa (Fig. 22). O sistema vascular da nervura mediana é bicolateral em $D$. chiqui- tana (Fig. 20-21) e D. nervosa (Fig. 22-23), bicolateral nas folhas das rosetas e nas regiões basal e mediana das folhas opostas cruzadas de $D$. pallescens (Fig. 16-17) e $D$. erubescens (Fig. 18-19) e colateral na região apical destas folhas. Associados ao feixe da nervura mediana notam-se esclereídes e fibras na base e na região mediana da folha oposta cruzada de $D$. pallescens (Fig. 17) e nas folhas de $D$. erubescens. Em D. nervosa (Fig. 22-23) são identificadas
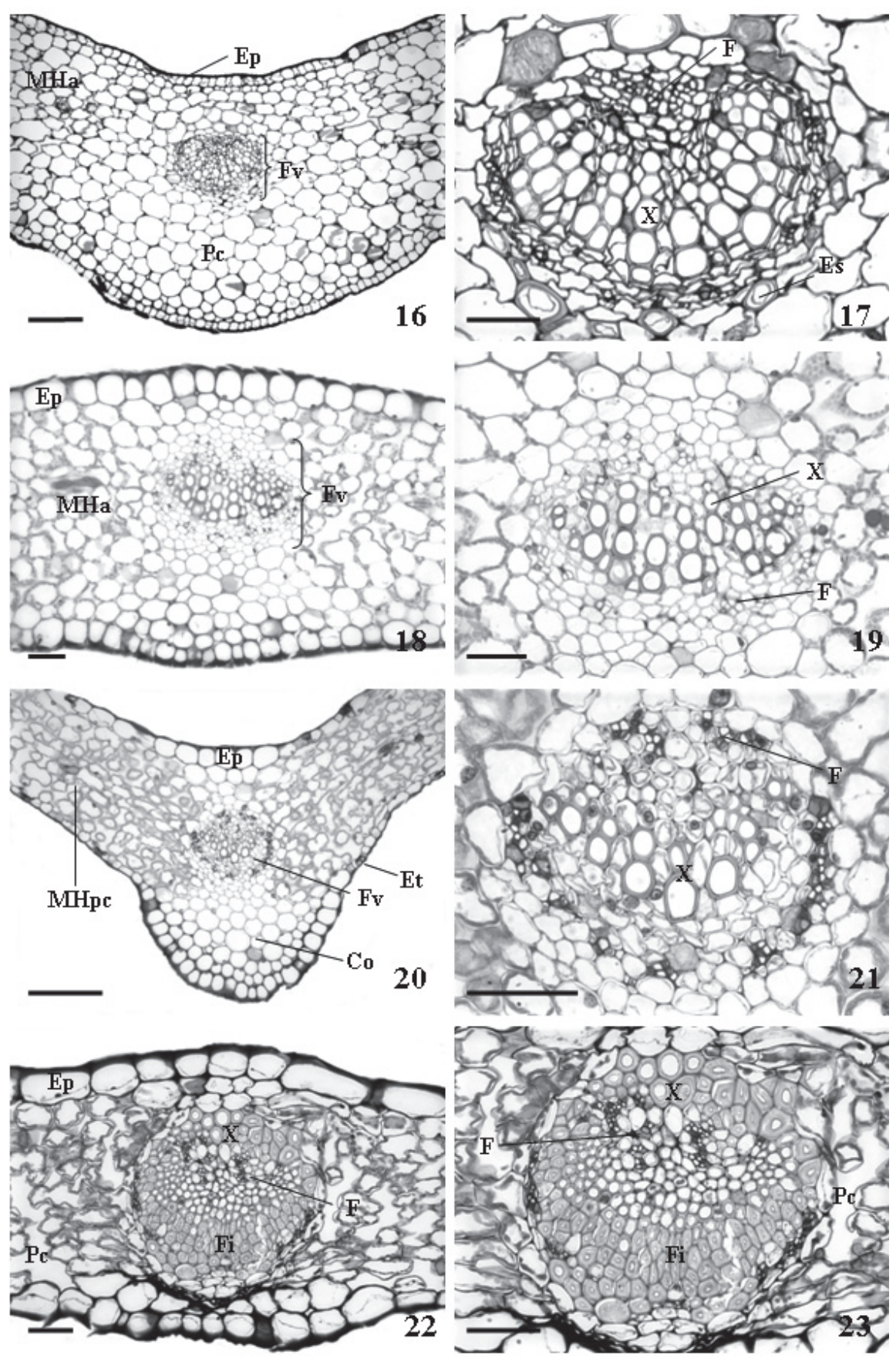

Figuras 16-23. Nervura mediana das folhas opostas cruzadas. 16-17. Região basal da folha de Deianira pallescens Cham. \& Schltdl. 18-19. Região mediana da folha de Deianira erubescens Cham. \& Schltdl. 20-21. Região mediana da folha de Deianira chiquitana Herzog. 22-23. Região apical da folha de Deianira nervosa Cham. \& Schltdl. Ep- epiderme, MHa- mesofilo homogêneo armazenador de água, Fv- feixe vascular, Pc- parênquima cortical, F- floema, X- xilema, Es- esclereídes, MHpc- mesofilo homogêneo formado por parênquima clorofiliano, Co- colênquima, Fi- calota de fibras. Escalas = 150 $\mu \mathrm{m}(16,20) ; 50 \mu \mathrm{m}(17,18,19,21,22,23)$. 
fibras que formam uma calota circundando o feixe. Nota-se colênquima subepidérmico voltado para a face abaxial na nervura mediana das folhas de D. chiquitana (Fig. 20) e das rosetas de $D$. erubescens e $D$. pallescens. A estrutura da margem da folha não apresenta uma variação pronunciada entre as espécies analisadas, sendo parenquimática em $D$. pallescens, $D$. erubecens e $D$. chiquitana e colenquimática em $D$. nervosa.
As paredes anticlinais das células epidérmicas das folhas de Schultesia gracilis (Tab. 3) são menos sinuosas na face adaxial e muito sinuosas na face abaxial. As paredes periclinais externas são lisas nas duas faces da folha e a cutícula é lisa e fina, sendo espessa apenas na região basal da face abaxial. As células epidérmicas são altas em secção transversal. As folhas de S. gracilis são hipoestomáticas (Fig. 29), sendo que o tipo preponderante de estômatos encontrados é o ano-
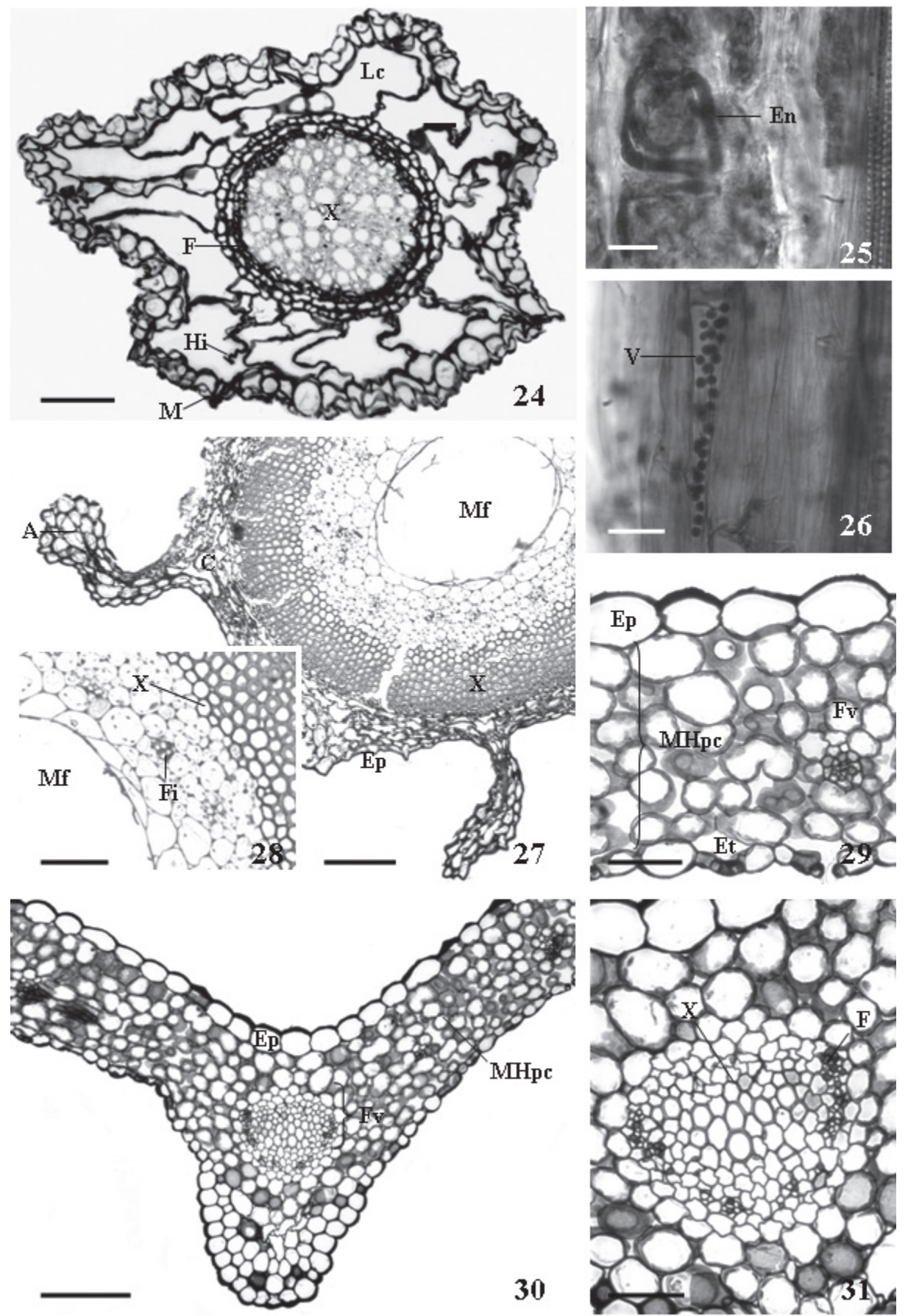

Figuras 24-31. Schultesia gracilis Mart. 24-26. Raiz. 27-28. Caule. 29-31. Folha. M - micorriza arbuscular do tipo Paris, Hi- hifas, Lc- lacuna de ar, F- floema, X- xilema, En- enovelamento de hifas, V- vesículas, A- aleta, Ep- epiderme, C- córtex, Fi- floema interno, Mf- medula fistulosa, Et- estômato, Fv- feixe vascular, MHpc- mesofilo homogêneo formado por parênquima clorofiliano. Escalas $=100 \mu \mathrm{m}(24,27) ; 10 \mu \mathrm{m}(25,26) ; 50 \mu \mathrm{m}(28,29,31) ; 150 \mu \mathrm{m}(30)$. 
mocítico. Em toda a extensão foliar, o mesofilo é homogêneo formado apenas por parênquima clorofiliano (Fig. 29-30). Em S. gracilis, a nervura mediana é muito proeminente (Fig. 30) e seu feixe vascular é bicolateral na base e colateral na região mediana (Fig. 31) e no ápice da folha. A margem da folha é formada por parênquima clorofiliano.

\section{Discussão}

As comparações entre os gêneros demonstram que Schultesia e Deianira apresentam atributos que são diagnósticos enquanto outros são compartilhados. Schultesia apresenta algumas características diagnósticas como raízes com aerênquima, MAs do tipo Paris, caule tetragonal e alado, nervura principal formada por feixe vascular colateral na região mediana da folha e estômatos anomocíticos. Por outro lado, a maioria das características morfo-anatômicas das folhas de Schultesia gracilis são atributos compartilhados com algumas espécies de Deianira: presença de um único tipo de folha e de folhas hipoestomáticas como observadas em Deianira nervosa, cutícula lisa nas folhas, como ocorre em Deianira erubescens, Deianira pallescens e Deianira chiquitana e mesofilo homogêneo formado por parênquima clorofiliano como visualizado em $D$. chiquitana.

Deianira apresenta como características diagnósticas do gênero raízes com crescimento usual ou não usual, MAs do tipo Arum, caule cilíndrico com epiderme com parede periclinal externa espessa, nervura principal formada por feixe vascular bicolateral na região mediana da folha e estômatos anisocíticos. As comparações infra-genéricas mostram que Deinaira nervosa é a espécie menos similar, pois há mais atributos morfo-anatômicos que a distinguem das demais espécies de Deianira, como: folhas com cutícula ornamentada, calota de fibras associadas ao feixe da nervura mediana, mesofilo do tipo dorsiventral e folha hipoestomática. A presença da heterofilia é um caráter compartilhado entre Deianira chiquitana, Deianira erubecens e Deianira pallescens, assim como algumas características anatômicas foliares tais como cutícula lisa e estômatos nas duas faces. Porém, D. erubecens e D. pallescens são mais similares por apresentarem mais características anatômicas compartilhadas, como mesofilo homogêneo armazenador de água nos dois tipos foliares e esclereídes e fibras associadas ao feixe da nervura mediana nas regiões basal e mediana das folhas opostas cruzadas.

As células epidérmicas do caule das espécies analisadas apresentam cutícula muito tênue conforme descrição do gênero Deianira (Guimarães 1977). A cutícula das espécies de Deianira é lisa enquanto que em Schultesia gracilis a cutícula é ornamentada. A ornamentação cuticular visível em microscopia de luz pode ser considerada uma característica diagnóstica na taxonomia (Metcalfe \& Chalk 1950). No caule, a presença de floema interno é característica da família Gentianaceae (Solereder 1908; Barroso et al. 1991). Em Deianira pallescens e S. gracilis, a medula parenquimática é fistulosa, sendo que a presença de caule fistuloso em $D$. pallescens é uma característica diagnóstica para a espécie de acordo com Guimarães (1977).

Nas folhas dispostas em roseta as células epidérmicas são, em corte transversal, tabulares em Deianira erubescens e altas em Deianira pallescens. O tamanho das células da epiderme e sua conformação apesar de serem caracteres plásticos, podem ser usados na identificação das espécies de $D$. erubescens e $D$. pallescens. Tal atributo anatômico é bastante útil uma vez que as duas espécies são indistinguíveis quando apresentam apenas rosetas. Por outro lado, o formato das células epidérmicas das folhas opostas cruzadas nas espécies analisadas varia de isodiamétrico a tabular dependendo da região foliar observada. Por isso, não é conveniente utilizar tal caráter anatômico para a distinção das espécies. Esta afirmação só é possível com análises anatômicas nas três regiões das folhas opostas cruzadas, demonstrando a importância de se estudar a lâmina foliar em diversas regiões.

As espécies de Deianira são anfiestomáticas, exceto Deianira nervosa que é hipoestomática. Os resultados obtidos são semelhantes aos dados de Guimarães (1977) e podem ser usados na identificação de $D$. nervosa que é muito semelhante à Deianira chiquitana no campo.

O mesofilo homogêneo de Deianira erubescens e Deianira pallescens, por apresentar células incolores, volumosas e com paredes finas, pode ser interpretado como mesofilo homogêneo armazenador de água (Dickson 2000). Tal atributo é diagnóstico para a identificação das duas espécies e pode ser avaliado como característica xeromórfica.

Esclereídes e fibras associadas ao feixe bicolateral das rosetas de Deianira erubescens são identificadas em cortes transversais. Isso constitui uma excelente ferramenta para a discriminação de $D$. erubescens, uma vez que a presença do esclerênquima é facilmente identificada por meio da confecção de lâminas a mão livre. Além disso, durante o período da seca apenas as rosetas permanecem quando caule e folhas opostas cruzadas estão secos, sendo impossível discriminar Deianira pallescens e D. erubescens apenas por meio da morfologia externa.

Na base e na região mediana da folha oposta cruzada de Deianira pallescens e em toda a extensão foliar de Deianira erubescens são observadas esclereídes e fibras circundando o feixe, já em Deianira nervosa observam-se calotas de fibras associadas ao feixe que contribuem para a consistência coriácea de suas folhas. Na nervura mediana das folhas de Deianira chiquitana é visualizado colênquima subepidérmico voltado para a face abaxial. Os tecidos mecânicos, especialmente associados aos feixes vasculares, permitem a estabilidade dos tecidos, o não colabamento celular em períodos de seca e o suporte contra ação dos ventos constantes em áreas abertas (Castro \& Menezes 1995).

O tipo de crescimento radicular nas espécies estudadas pode ser considerado um atributo taxonômico uma vez que Deianira erubescens e Deianira nervosa apresentam crescimento não usual enquanto que as outras espécies analisadas 
Tabela 3. Características morfo-anatômicas da folha de Deianira erubescens Cham. \& Schltdl., Deianira pallescens Cham. \& Schltdl., Deianira nervosa Cham. \& Schltdl., Deianira chiquitana Herzog e Schultesia gracilis Mart. $1=$ presença; $0=$ ausência; ad = adaxial; ab = abaxial; NM = nervura mediana.

\begin{tabular}{|c|c|c|c|c|c|}
\hline Tribo Chironieae / Espécies & D. erubescens & D. pallescens & D. nervosa & D. chiquitana & S. gracilis \\
\hline \multicolumn{6}{|l|}{ Roseta / Folha concrescida na base } \\
\hline Células epidérmicas da face ad tabulares & 1 & 0 & 0 & 0 & 0 \\
\hline Células epidérmicas da face ad altas & 0 & 1 & 0 & 1 & 0 \\
\hline Células epidérmicas da face ab tabulares & 1 & 0 & 0 & 0 & 0 \\
\hline Células epidérmicas da face ab altas & 0 & 1 & 0 & 1 & 0 \\
\hline Parede periclinal externa da face ad espessa & 0 & 0 & 0 & 1 & 0 \\
\hline Parede periclinal externa da face $a b$ espessa & 0 & 0 & 0 & 1 & 0 \\
\hline Cutícula da face ad lisa & 1 & 1 & 0 & 1 & 0 \\
\hline Cutícula da face ad ornamentada & 0 & 0 & 0 & 0 & 0 \\
\hline Cutícula da face ab lisa & 1 & 1 & 0 & 1 & 0 \\
\hline Cutícula da face ab ornamentada & 0 & 0 & 0 & 0 & 0 \\
\hline Folha anfiestomática & 1 & 1 & 0 & 1 & 0 \\
\hline NM com feixe vascular tipo bicolateral & 1 & 1 & 0 & 1 & 0 \\
\hline Esclereídes associados ao feixe da NM & 1 & 0 & 0 & 0 & 0 \\
\hline Fibras associadas ao feixe da NM & 1 & 0 & 0 & 0 & 0 \\
\hline Colênquima subepidérmico da face ab no córtex da NM & 1 & 1 & 0 & 1 & 0 \\
\hline Células da bainha formadas por esclereídes e fibras no feixe da NM & 1 & 0 & 0 & 0 & 0 \\
\hline Mesofilo homogêneo armazenador de água & 1 & 1 & 0 & 0 & 0 \\
\hline Mesofilo homogêneo com apenas parênquima clorofiliano & 0 & 0 & 0 & 1 & 0 \\
\hline Mesofilo dorsiventral & 0 & 0 & 0 & 0 & 0 \\
\hline \multicolumn{6}{|l|}{ Base da folha oposta cruzada } \\
\hline Células epidérmicas da face ad tabulares & 0 & 0 & 0 & 0 & 0 \\
\hline Células epidérmicas da face ad altas & 1 & 1 & 1 & 1 & 1 \\
\hline Células epidérmicas da face ab tabulares & 0 & 0 & 0 & 0 & 0 \\
\hline Células epidérmicas da face ab altas & 1 & 1 & 1 & 1 & 1 \\
\hline Parede periclinal externa da face ad espessa & 1 & 1 & 1 & 1 & 0 \\
\hline Parede periclinal externa da face $a b$ espessa & 1 & 1 & 1 & 0 & 0 \\
\hline Cutícula da face ad lisa & 1 & 1 & 1 & 1 & 1 \\
\hline Cutícula da face ad ornamentada & 0 & 0 & 1 & 0 & 0 \\
\hline Cutícula da face ab lisa & 1 & 1 & 0 & 1 & 1 \\
\hline Cutícula da face ab ornamentada & 0 & 0 & 1 & 0 & 0 \\
\hline Folha anfiestomática & 1 & 1 & 0 & 1 & 0 \\
\hline Folha hipoestomática & 0 & 0 & 1 & 0 & 1 \\
\hline Estômatos anomocíticos & 0 & 0 & 0 & 0 & 1 \\
\hline Estômatos anisocíticos & 1 & 1 & 1 & 1 & 0 \\
\hline NM com feixe vascular tipo bicolateral & 1 & 1 & 1 & 1 & 1 \\
\hline NM comfeixe vascular tipo colateral & 0 & 0 & 0 & 0 & 0 \\
\hline Esclereídes associados ao feixe da NM & 1 & 1 & 1 & 0 & 0 \\
\hline Fibras associados ao feixe da NM & 1 & 1 & 1 & 0 & 0 \\
\hline Colênquima subepidérmico da face $a b$ no córtex da NM & 0 & 0 & 0 & 1 & 0 \\
\hline Calota de fibras associada ao feixe da NM & 0 & 0 & 1 & 0 & 0 \\
\hline Mesofilo homogêneo armazenador de água & 1 & 1 & 0 & 0 & 1 \\
\hline Mesofilo homogêneo com apenas parênquima clorofiliano & 0 & 0 & 0 & 1 & 1 \\
\hline Mesofilo dorsiventral & 0 & 0 & 1 & 0 & 0 \\
\hline \multicolumn{6}{|l|}{ Região mediana da folha oposta cruzada } \\
\hline Células epidérmicas da face ad tabulares & 0 & 0 & 0 & 0 & 0 \\
\hline Células epidérmicas da face ad altas & 1 & 1 & 1 & 1 & 1 \\
\hline Células epidérmicas da face ab tabulares & 0 & 0 & 1 & 0 & 0 \\
\hline Células epidérmicas da face ab altas & 1 & 1 & 0 & 1 & 1 \\
\hline Parede periclinal externa da face ad espessa & 1 & 1 & 1 & 0 & 0 \\
\hline Parede periclinal externa da face $a b$ espessa & 1 & 0 & 1 & 0 & 0 \\
\hline Cutícula da face ad lisa & 1 & 0 & 1 & 1 & 1 \\
\hline Cutícula da face ad ornamentada & 0 & 0 & 1 & 0 & 0 \\
\hline Cutícula da face ab lisa & 1 & 1 & 0 & 1 & 1 \\
\hline Cutícula da face ab ornamentada & 0 & 0 & 1 & 0 & 0 \\
\hline Folha anfiestomática & 1 & 1 & 0 & 1 & 0 \\
\hline Folha hipoestomática & 0 & 0 & 1 & 0 & 1 \\
\hline Estômatos anomocíticos & 0 & 0 & 0 & 0 & 1 \\
\hline Estômatos anisocíticos & 1 & 1 & 1 & 1 & 0 \\
\hline NM com feixe vascular tipo bicolateral & 1 & 1 & 1 & 1 & 0 \\
\hline NM com feixe vascular tipo colateral & 0 & 0 & 0 & 0 & 1 \\
\hline Esclereídes associados ao feixe da NM & 1 & 1 & 1 & 0 & 0 \\
\hline Fibras associadas ao feixe da NM & 1 & 1 & 1 & 0 & 0 \\
\hline Colênquima subepidérmico da face ab no córtex da NM & 0 & 0 & 0 & 1 & 0 \\
\hline
\end{tabular}


Tabela 3 (Continuação).

\begin{tabular}{|c|c|c|c|c|c|}
\hline Tribo Chironieae / Espécies & D. erubescens & D. pallescens & D. nervosa & D. chiquitana & S. gracilis \\
\hline \multicolumn{6}{|l|}{ Região mediana da folha oposta cruzada } \\
\hline Calota de fibras associada ao feixe da NM & 0 & 0 & 1 & 0 & 0 \\
\hline Mesofilo homogêneo armazenador de água & 1 & 1 & 0 & 0 & 1 \\
\hline Mesofilo homogêneo com apenas parênquima clorofiliano & 0 & 0 & 0 & 1 & 1 \\
\hline Mesofilo dorsiventral & 0 & 0 & 1 & 0 & 0 \\
\hline \multicolumn{6}{|l|}{ Ápice da folha oposta cruzada } \\
\hline Células epidérmicas da face ad tabulares & 0 & 0 & 1 & 1 & 0 \\
\hline Células epidérmicas da face ad altas & 1 & 1 & 0 & 0 & 1 \\
\hline Células epidérmicas da face $a b$ tabulares & 1 & 0 & 1 & 1 & 0 \\
\hline Células epidérmicas da face $a b$ altas & 0 & 1 & 0 & 0 & 1 \\
\hline Parede periclinal externa da face ad espessa & 1 & 0 & 1 & 1 & 0 \\
\hline Parede periclinal externa da face $a b$ espessa & 1 & 0 & 1 & 1 & 0 \\
\hline Cutícula da face ad lisa & 1 & 1 & 1 & 1 & 1 \\
\hline Cutícula da face ad ornamentada & 0 & 0 & 1 & 0 & 0 \\
\hline Cutícula da face ab lisa & 1 & 1 & 0 & 1 & 1 \\
\hline Cutícula da face ab ornamentada & 0 & 0 & 1 & 0 & 0 \\
\hline Folha anfiestomática & 1 & 1 & 0 & 1 & 0 \\
\hline Folha hipoestomática & 0 & 0 & 1 & 0 & 1 \\
\hline Estômatos anomocíticos & 0 & 0 & 0 & 0 & 1 \\
\hline Estômatos anisocíticos & 1 & 1 & 1 & 1 & 0 \\
\hline NM com feixe vascular tipo bicolateral & 0 & 0 & 1 & 1 & 0 \\
\hline NM com feixe vascular tipo colateral & 1 & 1 & 0 & 0 & 1 \\
\hline Esclereídes associados ao feixe da NM & 1 & 0 & 1 & 0 & 0 \\
\hline Fibras associadas ao feixe da NM & 1 & 0 & 1 & 0 & 0 \\
\hline Colênquima subepidérmico da face ab no córtex da NM & 0 & 0 & 0 & 1 & 0 \\
\hline Calota de fibras associada ao feixe da NM & 0 & 0 & 1 & 0 & 0 \\
\hline Mesofilo homogêneo armazenador de água & 1 & 1 & 0 & 0 & 1 \\
\hline Mesofilo homogêneo com apenas parênquima clorofiliano & 0 & 0 & 0 & 1 & 1 \\
\hline Mesofilo dorsiventral & 0 & 0 & 1 & 0 & 0 \\
\hline
\end{tabular}

possuem crescimento usual. O crescimento não usual possui valor taxonômico em função da ocorrência restrita, apesar de já ter sido identificado para a família Gentianaceae nas raízes de algumas espécies de Eustoma, Gentiana e Swertia (Metcalfe \& Chalk 1983). O crescimento não usual também pode ser considerado uma notável adaptação às condições ambientais (Metcalfe \& Chalk 1983). O fato de se encontrar floema interxilemático nas regiões radiculares com maior diâmetro em $D$. erubescens e D. nervosa corrobora a teoria descrita por Fahn \& Shchori (1968) sobre a funcionalidade das porções de floema incluso. Para esses autores, os elementos do floema interxilemático transferem fotoassimilados para as várias regiões da raiz, facilitando o espessamento radicular e aumentando a eficiência de transporte. Outra possível vantagem da existência do floema interno cercado por vários elementos do xilema é a sua permanente atividade; uma vez que ele está protegido de possíveis condições adversas, enquanto que o floema presente na periferia do eixo pode tornar-se inativo durante tais condições (Fahn \& Shchori 1968; Paviani \& Haridasan 1988). O maior espessamento das raízes de $D$. erubescens e $D$. nervosa comparado com o espessamento das raízes de $D$. pallescens e D. chiquitana também pode ser justificado devido à atividade cambial não usual. Em algumas raízes tuberosas, a maior espessura da tuberosidade coincide com a presença do floema incluso como acontece em Vochysia thysoidea, espécie típica do cerrado (Paviani \& Haridasan 1988). Em outras espécies a tuberosidade é conseqüência do crescimento secundário não usual (Dabydeen \& Sirju-Charran 1990).
Em Schultesia gracilis, o aerênquima é o tecido presente no córtex das raízes. Os exemplares de $S$. gracilis estudados crescem em solos com muita matéria orgânica que permanecem encharcados durante a estação chuvosa. As plantas são observadas apenas no verão e no outono, sendo que, nesta estação, elas já estão secas, uma vez que apresentam ciclo de vida curto, restrito ao período das águas. Logo, o desenvolvimento radicular ocorre em condições de alagamento o que pode justificar a presença de aerênquima (Scatena \& Rocha 1995). A quantidade desse tecido na planta depende do genótipo do indivíduo e das condições ambientais (Colmer 2003).

Em Deianira pallescens e em Deianira chiquitana o córtex parenquimático apresenta conteúdo amilífero. $\mathrm{O}$ acúmulo de reserva é um indicativo da adaptação das espécies às condições estacionais e adversas encontradas no cerrado sensu stricto (Vilhalva \& Appezzato-da-Glória 2006). A predominância de parênquima de armazenamento nas raízes espessas pode ser um atributo para caracterizálas como raízes tuberosas (Appezzato-da-Glória \& Estelita 2000). O intumescimento nas raízes mais velhas de $D$. pallescens também foi observado por Guimarães (1977) e permite classificá-las como raízes tuberosas. Por outro lado, as raízes de $D$. chiquitana apesar de apresentarem conteúdo amilífero não podem ser identificadas como raízes do tipo tuberosas por serem mais finas. Nas raízes de maior diâmetro, como as que ocorrem em Deianira erubescens, Deianira pallescens e Deianira nervosa, a 
epiderme e algumas camadas do córtex são descartadas em virtude do espessamento do órgão. Em $D$. erubescens e $D$. pallescens, as camadas corticais descartadas apresentam micorrizas arbusculares do tipo Arum que podem facilitar a absorção de fósforo e de outros nutrientes para as plantas (Gross et al. 2003).

Micorrizas arbusculares (MAs) são observadas nas raízes de todas as espécies, exceto em $D$. nervosa em conseqüência, provavelmente, de terem sido coletadas raízes muito espessas. A ocorrência generalizada das MAs nas plantas vasculares foi confirmada por diversos autores, sendo também pronunciada a existência de MA em diversas espécies de cerrado (Thomazini 1974; Carneiro et al. 1998; Detmann et al. 2008), o que torna provável a presença das MAs em Deianira nervosa.

As micorrizas aumentam o acesso a nutrientes e água, fundamentais para a sobrevivência das plantas (Siqueira et al. 2002; Peterson et al. 2004), uma vez que as condições abióticas do cerrado e do campo rupestre, como alta irradiância e solos pobres em nutrientes, determinam limitações fisiológicas para as plantas nativas. O controle do excesso de transpiração em plantas sob alta irradiância e calor, resulta em diminuição da fotossíntese (Franco \& Lüttge 2002), além disso, as herbáceas do cerrado e do campo rupestre podem estar submetidas ao déficit hídrico.

As espécies Deianira erubescens, Deianira pallescens e Deianira chiquitana apresentam MA do tipo Arum enquanto que Schultesia gracilis apresenta MA do tipo Paris. A micorriza arbuscular do tipo Arum é formada por hifas que percorrem o apoplasto do córtex antes de formarem os arbúsculos dentro das células e a micorriza arbuscular do tipo Paris se caracteriza predominantemente por apresentar enovelamentos de hifas intracelulares (Peterson et al. 2004). Apesar da ocorrência da micorriza do tipo Arum na maioria das espécies de Deianira coletadas no campo, em plantas arbóreas e herbáceas de cerrado foram indicadas MAs do tipo Paris e Arum (Detmann et al. 2008), porém tem sido sugerida uma predominância do tipo Paris em condições naturais em espécies de diversos grupos (Smith \& Smith 1997). Isto ocorre, provavelmente, porque MA do tipo Paris é interpretada como a melhor estratégia de micorrização para plantas sob fortes fatores limitantes e baixas condições nutricionais (Weber et al. 1995). O resultado de micorrização intensa por MA do tipo Paris em $S$. gracilis corrobora a interpretação de que tal tipo de micorriza é mais vantajoso em condições estressantes. Plantas estudadas de S. gracilis estão submetidas às intensas condições adversas como alagamento, hipoxia, baixa disponibilidade de nutrientes e alta irradiação.

A escassez de estudos anatômicos sobre as plantas herbáceas de cerrado e as eudicotiledôneas dos campos rupestres assim como análises que comprovem a existência de associação micorrízica em herbáceas nativas de cerrado e campo rupestre tornam o presente trabalho ferramenta importante para a compreensão da grande riqueza estrutural existente nos biomas cerrado e campo rupestre.

\section{Agradecimentos}

Gostaríamos de agradecer à professora Elsie Franklin Guimarães pela identificação do material, a botânica Cristina Ribeiro Marinho pelas sugestões na elaboração do artigo, aos funcionários da Floresta Nacional de Paraopeba por permitirem as nossas coletas e ao Conselho Nacional de Pesquisa $(\mathrm{CNPq})$ pela concessão da bolsa de mestrado.

\section{Referências bibliográficas}

Albert, V.A. \& Struwe, L. 2002. Gentianaceae in context. . In: L. Struwe \& V.A. Albert (eds.). Gentianaceae: Systematics and Natural History. Cambridge, Cambridge University Press.

Appezzato-da-Glória, B. \& Estelita, M.E.M. 2000. The developmental anatomy of the subterranean system in Mandevilla illustris (Vell.) Woodson and M. velutina (Mart. Ex Stadelm.) Woodson (Apocynaceae). Revista Brasileira de Botânica 23(1): 27-35.

Arens, K. 1963. As plantas lenhosas dos campos cerrados como flora adaptada às deficiências minerais do solo. In: M.G. Ferri (ed.). Simpósio sobre o Cerrado. São Paulo, Editora Edgar Blucher e EDUSP.

Barroso, G.M.; Peixoto, A.L.; Ichaso, C.L.F.; Guimarães, E.F. \& Costa, C.G. 1991. Sistemática das Angiospermas do Brasil. Vol. 3. Viçosa, Editora UFV.

Berlyn, G.P. \& Miksche, J.P. 1976. Botanical microtechnique and cytochemistry. Ames, The Iowa States Press.

Brundett, M.C.; Bougher, N.; Dell, B.; Grove, T. \& Malajczu, N. 1996. Working with mycorrhizas in forest and agriculture. Gamberra, ACIAR Pirie.

Carneiro, M.A.; Siqueira, J.O.; Moreira, F.M.S.; Carvalho, D.; Botelho, S.A. \& Junior, O.J.S. 1998. Micorriza arbuscular em espécies arbóreas e arbustivas nativas de ocorrência no sudeste do Brasil. Cerne 4(1): 129-145.

Castro, N.M. \& Menezes, N.L. 1995. Aspectos da anatomia foliar de algumas espécies de Paepalanthus Kunth, Eriocaulaceae da Serra do Cipó (Minas Gerais). Acta Botanica Brasilica 9(2): 213-229.

Colmer, T.D. 2003. Long-distance transport of gases in plants: a perspective on internal aeration and radial oxygen loss from roots. Plant, Cell \& Enviroments 26: 17-36

Coutinho, L.M. 2002. O bioma do cerrado. In: A.L. Klein (ed.). Eugen Warming e o cerrado brasileiro: um século depois. São Paulo, Editora Unesp.

Dabydeen, S. \& Sirju-Charran, G. 1990. The developmental anatomy of the root system in yam bean, Pachyrhizus erosus Urban. Annals of Botany 66: 313-320.

Detmann, K.S.C.; Delgado, M.N.; Rebello, V.P.A.; Leite, T.S.; Azevedo, A.A.; Kasuya, M.C.M. \& Almeida, A.M. 2008. Comparação de métodos para a observação de fungos micorrízicos arbusculares e endofíticos do tipo dark septate em espécies nativas de cerrado. Revista Brasileira de Ciência do Solo 32: 1883-1890.

Dickison, W.C. 2000. Integrative Plant Anatomy. New York, Harcourt Academic Press

Fahn, A. \& Shchori, Y. 1968. The organization of secondary conducting tissues in some species of the Chenopodiaceae. Phytomorphology 17: $147-154$.

Franco, A.C. 1998. Seasonal patterns of gas exchange, water relations and growth of Roupala montana, an evergreen species. Plant Ecology 136: 69-76.

Franco, A.C. 2002. Ecophysiology of cerrado woody plants. In: P.S. Oliveira \& R.J. Marquis (eds.). The cerrados of Brazil: ecology and natural history of a neotropical savanna. New York, Columbia University Press,

Franco, A.C. \& Lüttge, U. 2002. Midday depression in savanna trees: coordinated adjustments in photochemical, efficiency, photorespiration, $\mathrm{CO}$ assimilation and water use efficiency. Oecologia 131: 356-365.

Furley, P.A. \& Ratter, J.A. 1988. Soil resources and plant communities of the central brazilian cerrado and their development. Journal of Biogeographic 15: 97-108.

Gross, E.; Cordeiro, L. \& Caetano, F.H. 2003. Anatomical and ultraestructural aspects of root and mycorrhiza of Anadenanthera peregrina (L.) Speg. Var. falcate (Benth.) Altschul (Leguminosae- 
Mimosoideae). Revista Brasileira de Botânica 26(4): 515-523.

Giulietti, A.M., Menezes, N.L., Pirani, J.R., Meguro, M. \& Wanderley, M.G.L. 1987. Flora da Serra do Cipó, Minas Gerais: caracterização e lista das espécies. Boletim de Botânica da Universidade de São Paulo 9: 1-115.

Guimarães, E.F. 1977. Revisão taxonômica do gênero Deianira Chamisso et Schlechtendal (Gentianaceae). Arquivo do Jardim Botânico do Rio de Janeiro 21: 45-123.

Guimarães, E.F. 2004. Novos sinônimos para espécies de Schultesia Mart. e Xestaea Griseb. (Gentianaceae). Rodriguésia 55 (85): 67-72.

Guimarães, E.F. \& Klein, V.L.G. 1985. Revisão taxonômica do gênero Coutoubea Aublet (Gentianaceae). Rodriguésia 37: 21-45.

Herrman, S.; Oelmmuller, R. \& Buscot, F. 2004. Manipulation of the onset of ectomycorrhyza formation by indole-3-acetic acid, activated charcoal or relative humidity in the association between oak micronuttines and Piloderma croceum influence on plant development and photosynthesis. Journal of Plant Physiology 161: 509-17.

Johansen, D.A. 1940. Plant Microtechnique. New York, McGraw Hill Book Co. Inc.

Lacher, W. 2004. Ecofisiologia Vegetal. São Carlos, RiMa.

Mansion, G. 2004. A new classification of the polyphyletic genus Centaurium Hill (Chironiinae, Gentianaceae): description of the New World endemic Zeltnera, and reinstatement of Gyrandra Griseb. and Schenkia Griseb. Taxon 53 (3):719-740.

Mansion, G. \& Struwe, L. 2004. Generic delimitation and phylogenetic relationships within the subtribe Chironiinae (Chironieae: Gentianaceae), with special reference to Centaurium: evidence from nrDNA and cpDNA sequences. Molecular Phylogenetics and Evolution 32: 951-977.

Mendonça, R.C.; Filgueiras, T.S. \& Fagg, C.W. 2007. Análise florística da chapada dos Veadeiros. In: J.M. Felfili, A.V. Rezende \& M.C. Silva-Jr (eds.) Biogeografia do bioma cerrado: vegetação e solos da Chapada dos Veadeiros. Brasília, Editora UnB.

Meszaros, S.; Laet, J. \& Smets, E. 1996. Phylogeny of temperate Gentianaceae: a morphological approach. Systematic Botany 21(2): 153-168.

Metcalfe, C.F. \& Chalk, L. 1950. Anatomy of the Dicotyledons: leaves, stem and wood in relation to taxonomy with notes on economic uses. Oxford, Clarendon Press.
Metcalfe, C.F. \& Chalk, L. 1983. Anatomy of the Dicotyledons: Wood structure and conclusion of the general introduction. 2 ed. New York, Oxford Science Publications.

O’Brien, T.P. \& McCully, M.E. 1981. The study of structure principles and selected methods. Melbourne, Termarcarphi Pty. LTD.

Paviani, T.I. \& Haridasan, M. 1988. Tuberosidade em Vochysia thyrsoidea Pohl (Vochysiaceae). Ciência e Cultura 40(10): 998-1003.

Peterson, R.L.; Massicotte, H.B. \& Melville, L.H. 2004. Mycorrhizas: anatomy and cell biology. Ottawa, NRC Research Press.

Phillips, J.M. \& Hayman, D.S. 1970. Improved procedures for clearing roots and staining parasitic and vesicular arbuscular mycorrhizal fungi for rapid assessment of infection. Transactions of the British Mycological Society 55: 158-160.

Scatena, V.L. \& Rocha, C.L.M. 1995. Anatomia dos órgãos vegetativos e do escapo floral de Leiothrix crassifolia (Bong). Ruhl., Eriocaulaceae, da Serra do Cipó - MG. Acta Botanica Brasilica 9 (2): 195-211.

Smith, F.A. \& Smith, S.E. 1997. Structural diversity in vesicular-arbuscular mycorrhizal symbioses. New Phytology 137: 373-388.

Siqueira, J.O.; Lambais, M.R. \& Stumer, S.L. 2002. Fungos Micorrízicos Arbusculares. Biologia, Ciência e Desenvolvimento 25: 12-21.

Solereder, H. 1908. Systematic Anatomy of the Dicotiledons. Vol. 1. Oxford, Claredon Press.

Sousa, V.C. \& Lorenzi, H. 2005. Botânica Sistemática. São Paulo, Instituto Plantarum de Estudos da Flora Ltda.

Struwe, L.; Kadereit, J.W.; Klackenberg, J.; Nilsson, S.; Thiv, M.; Von-Hagen, K.B. \& Albert, V.A. 2002. Systematics, character evolution, and biogeography of Gentianaceae, including a new tribal and subtribal classification. In: L. Struwe \& V.A. Albert (eds.). Gentianaceae: Systematics and Natural History. Cambridge, Cambridge University Press.

Thomazini, L.I. 1974. Mycorrhiza in plants of the cerrado. Plant and Soil 41: 707-711.

Vilhalva, D.A.A. \& Appezzato-da-Glória, B. 2006. Morfoanatomia da raiz tuberosa de Vernonia oxylepis Sch. Bip. in Mart. ex Baker-Asteraceae. Acta Botanica Brasilica 20(3): 591-598.

Weber, H.C.; Klahr, A. \& Marron-Heimbuch, M. 1995. Anatomical structures of the VA mycorrhizal in Apocynaceae (Gentianales). Botanica Acta 108: 525-534. 